\title{
p-Hydroxycinnamyl aldehydes in lignifying plant cell walls
}

\author{
Laura V. Gómez-Ros, ${ }^{a} J_{0 s e}$ M. Espiñeira, ${ }^{b}$ F. Pomar, ${ }^{b, c}$ María J. L. Núñez-Flores ${ }^{a}$ and \\ A. Ros Barceló ${ }^{\text {a* }}$ \\ ${ }^{a}$ Department of Plant Biology, University of Murcia, E-30100 Murcia, Spain \\ ${ }^{b}$ Department of Plant Biology, University of La Coruña, E-15071 La Coruña, Spain \\ ${ }^{c}$ CIA de Mabegondo, Apartado de Correos 10, E-15080 La Coruña, Spain \\ E-mail: rosbarce@um.es
}

Dedicated to Professor Atta-ur-Rahman on the occasion of his $65^{\text {th }}$ anniversary

\begin{abstract}
The incorporation of $p$-hydroxycinnamyl aldehydes 5-6 into the $\beta-O-4$ fraction of lignins was studied by thioacidolysis in twelve differentially evolved land plant species, including lycopods and ferns. The results showed that compounds 5-6 may be detected in all studied species, as could be predicted from the reversible nature of the $p$-hydroxycinnamyl alcohol dehydrogenase (CAD) catalyzed reaction. The results also showed that the $p$-hydroxycinnamyl alcohol $/ p$ hydroxycinnamyl aldehyde ratio has been conserved during land plant evolution.
\end{abstract}

Keywords: $\beta$ - $O-4$ Lineal lignin fraction, $p$-hydroxycinnamyl alcohols, $p$-hydroxycinnamyl aldehydes, lignification

\section{Introduction}

Lignins are phenolic heteropolymers which mainly result from the oxidative coupling of the three $p$-hydroxycinnamyl alcohols (monolignols), $p$-coumaryl (1), coniferyl (2) and sinapyl (3), in a reaction mediated by peroxidases. ${ }^{1}$ The cross-coupling reaction produces an optically inactive hydrophobic heteropolymer composed of $p$-hydroxyphenyl $(\mathrm{H})$, guaiacyl $(\mathrm{G})$, and syringyl (S) units, respectively. ${ }^{2}$ Both the $G$ and $S$ phenylpropanoid units in lignins are interconnected by means of a series of ether and carbon-carbon linkages, the most frequent being the $\beta-O-4$ bonds present in guaiacyl-glycerol- $\beta$-aryl ether substructures, ${ }^{2}$ which are the targets of lignin depolymerization processes, such as thioacidolysis. ${ }^{3}$ 
<smiles>[R]c1cc(/C=C/CO)cc([R])c1O</smiles><smiles>[R]c1cc(/C=C/C=O)cc([R])c1O</smiles>

$$
\begin{aligned}
& 1 \mathrm{R}_{1}=\mathrm{R}_{2}=\mathrm{H} \\
& 2 \mathrm{R}_{1}=\mathrm{H} ; \mathrm{R}_{2}=\mathrm{OCH}_{3} \\
& 3 \mathrm{R}_{1}=\mathrm{R}_{2}=\mathrm{OCH}_{3}
\end{aligned}
$$

$4 \mathrm{R}_{1}=\mathrm{R}_{2}=\mathrm{H}$

$5 \mathrm{R}_{1}=\mathrm{H} ; \mathrm{R}_{2}=\mathrm{OCH}_{3}$

$6 \mathrm{R}_{1}=\mathrm{R}_{2}=\mathrm{OCH}_{3}$

Although most of the building blocks found in natural lignins are derived from the three $p$ hydroxycinnamyl alcohols (1-3), recent evidence has suggested that at least two $p$ hydroxycinnamyl aldehydes (coniferyl $\mathbf{5}$ and sinapyl $\mathbf{6}$ aldehydes) are also incorporated in the growing lignin polymer, a situation which is especially evident in cinnamyl alcohol dehydrogenase (CAD) depleted mutant or transgenic plants. ${ }^{4,5}$ These $p$ hydroxycinnamylaldehydes 5-6 may then be deposited in the xylem cell walls, where they copolymerize with 2-3 to yield a highly heterogeneous alcohol/aldehyde lignin polymer, in which 6 $\beta-O-4$ cross-couples with both $\mathrm{G}$ and $\mathrm{S}$ units, whereas 5 cross-couples only with $\mathrm{S}$ units (Scheme $1)^{4}$. This escape of $p$-hydroxycinnamyl aldehydes from reduction to $p$-hydroxycinnamyl alcohols is co-substantial with the nature of the CAD catalyzed reaction. In fact, CAD catalyzes the following equilibrium reaction:

$$
\text { Cinnamyl aldehyde }+\mathrm{NADPH}+\mathrm{H}^{+} \longleftrightarrow \text { Cinnamyl alcohol }+\mathrm{NADP}^{+}
$$

This means that if $p$-hydroxycinnamyl alcohols 1-3 are not removed either by transport or conjugation, a certain amount of $p$-hydroxycinnamyl aldehydes, depending on the $\mathrm{NADPH} / \mathrm{NADP}^{+}$cellular pool, will escape from the CAD-mediated reduction. It might therefore be expected that these aldehydes, together with their corresponding alcohols, would ultimately be incorporated into cell wall lignins. However, until now it has not been clear whether $p$ hydroxycinnamyl aldehydes 5-6 were incorporated into lignins at an early or a later stage during land plant evolution.

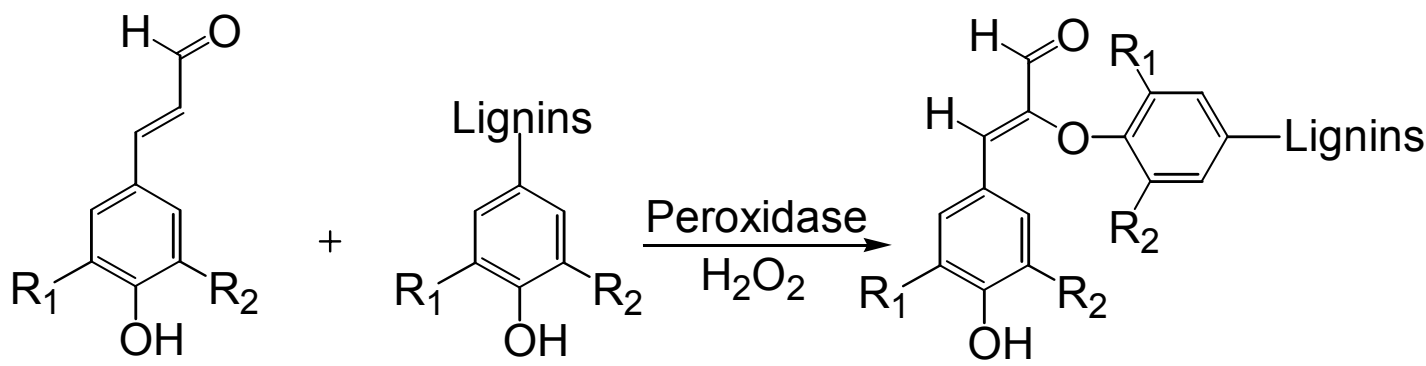
$5 \mathrm{R}_{1}=\mathrm{H} ; \mathrm{R}_{2}=\mathrm{OCH}_{3}$
$6 \mathrm{R}_{1}=\mathrm{R}_{2}=\mathrm{OCH}_{3}$
$2 \mathrm{R}_{1}=\mathrm{H} ; \mathrm{R}_{2}=\mathrm{OCH}_{3}$
$3 \mathrm{R}_{1}=\mathrm{R}_{2}=\mathrm{OCH}_{3}$

\section{Scheme 1}


To answer this question, we show in this report that the $p$-hydroxycinnamyl alcohol $/ p$ hydroxycinnamyl aldehyde ratio of the $\beta-O-4$ lignin fraction is independent of the lignin monomer composition in differentially evolved land plant species, and that these ratios have largely been conserved during land plant evolution.

\section{Results and Discussion}

Thioacidolysis is a selective technique which breaks down the predominant inter-unit linkages in lignins from plant cell walls, specifically the aryl-glycerol- $\beta$-aryl ether $(\beta-O-4)$ bonds, ${ }^{3}$ the frequencies of which vary from $50 \%$ in gymnosperms to $80 \%$ in angiosperms. ${ }^{1}$ Analysis by thioacidolysis of cell wall lignins in differentially evolved plant species reveals (Table 1) that gymnosperm lignins (samples 4-9) are typically composed of $\mathrm{G}$ units, while angiosperm lignins are mainly composed of similar levels of $\mathrm{G}$ and $\mathrm{S}$ units (samples 1-3). In most basal vascular plant orders, such as lycopods (sample 10) and ferns (samples 11-12), lignins are mainly composed of similar levels of $\mathrm{G}$ and $\mathrm{S}$ units, or are typically composed of $\mathrm{G}$ units, respectively.

Table 1. $\beta-O-4$ Linked degradation products obtained by thioacidolysis of lignifying plant cell walls of angiosperms (samples 1-3), gymnosperms (samples 4-9), lycopods (sample 10) and ferns (samples 11-12)

\begin{tabular}{llcccccc}
\hline \multirow{2}{*}{ Sample } & Plant species & \multicolumn{3}{c}{$\beta-O-4$ linked G units } & \multicolumn{3}{c}{$\beta-O-4$ linked S units } \\
\cline { 3 - 8 } & & $\mathbf{7}$ & $\mathbf{9}$ & $\mathbf{7 / 9}$ & $\mathbf{8}$ & $\mathbf{1 0}$ & $\mathbf{8} / \mathbf{1 0}$ \\
\hline 1 & Zinnia elegans & 10.43 & 0.48 & 21.73 & 13.85 & 0.45 & 30.81 \\
2 & Capsicum annuum & 22.60 & 0.70 & 32.34 & 11.48 & 0.74 & 15.49 \\
3 & Populus alba & 1.40 & 0.05 & 28.02 & 2.05 & 0.09 & 22.78 \\
4 & Ephedra viridis & 0.39 & 0.03 & 13.04 & 0.64 & 0.04 & 16.03 \\
5 & Pinus halepensis & 2.26 & 0.40 & 5.65 & $\mathrm{Nd}$ & $\mathrm{Nd}$ & $\mathrm{Nc}$ \\
6 & Araucaria araucana & 0.58 & 0.05 & 11.61 & 0.01 & $\mathrm{Nd}$ & $\mathrm{Nc}$ \\
7 & Araucaria heterophylla & 3.06 & 0.29 & 10.51 & 0.14 & $\mathrm{Nd}$ & $\mathrm{Nc}$ \\
8 & Taxus baccata & 0.64 & 0.05 & 12.83 & 0.01 & $\mathrm{Nd}$ & $\mathrm{Nc}$ \\
9 & Gingko biloba & 0.51 & 0.06 & 8.53 & 0.02 & $\mathrm{Nd}$ & $\mathrm{Nc}$ \\
10 & Sellaginella martensii & 0.64 & 0.07 & 9.14 & 1.90 & 0.21 & 9.01 \\
11 & Pteridium aquilinum & 0.64 & 0.02 & 32.03 & $\mathrm{Nd}$ & $\mathrm{Nd}$ & $\mathrm{Nc}$ \\
12 & Dryopteris filis-max & 0.57 & 0.03 & 19.01 & $\mathrm{Nd}$ & $\mathrm{Nd}$ & $\mathrm{Nc}$ \\
\hline
\end{tabular}

Values are given as total ionic current (TIC) $x 10^{-8} . \mathrm{Nd}$, not detected. Nc, not calculated.

A detailed fingerprint of the thioethylated monomers arising from thioacidolysis analysis revealed the almost universal presence of aryl-glycerol- $\beta$-aryl ether structures derived from coniferyl alcohol 7 (Scheme 2), a compound which was found in all the angiosperms (samples 1- 
3), gymnosperms (samples 4-9), lycopods (sample 10) and ferns (samples 11-12) studied. The presence of aryl-glycerol- $\beta$-aryl ether structures derived from sinapyl alcohol $\mathbf{8}$ was also observed in almost all the phyla, with the exception of ferns.

Aryl-glyceraldehyde- $\beta$-aryl ether structures (Scheme 2 ) derived from coniferyl aldehyde 9 were also observed in almost all the phyla, while aryl-glyceraldehyde- $\beta$-aryl ether structures derived from sinapyl aldehyde 10 were only seen in angiosperms (samples 1-3), gymnosperms belonging to Gnetales (sample 4) and lycopods (sample 10), but never in other gymnosperms and ferns.

Given such a scenario, these results demonstrate that the incorporation of $p$ hydroxycinnamyl aldehydes 5-6 into lignins was an early event during the land plant evolution, since aldehydes are detected not only in lycopods but also in ferns. Most importantly, the $p$ hydroxycinnamyl alcohol/ $p$-hydroxycinnamyl aldehyde ratios of the $\beta-O-4$ lignin fraction were independent on the lignin monomer composition in these differentially evolved land plant species, in which they varied between 5.6 and 32, with mean values around 17.
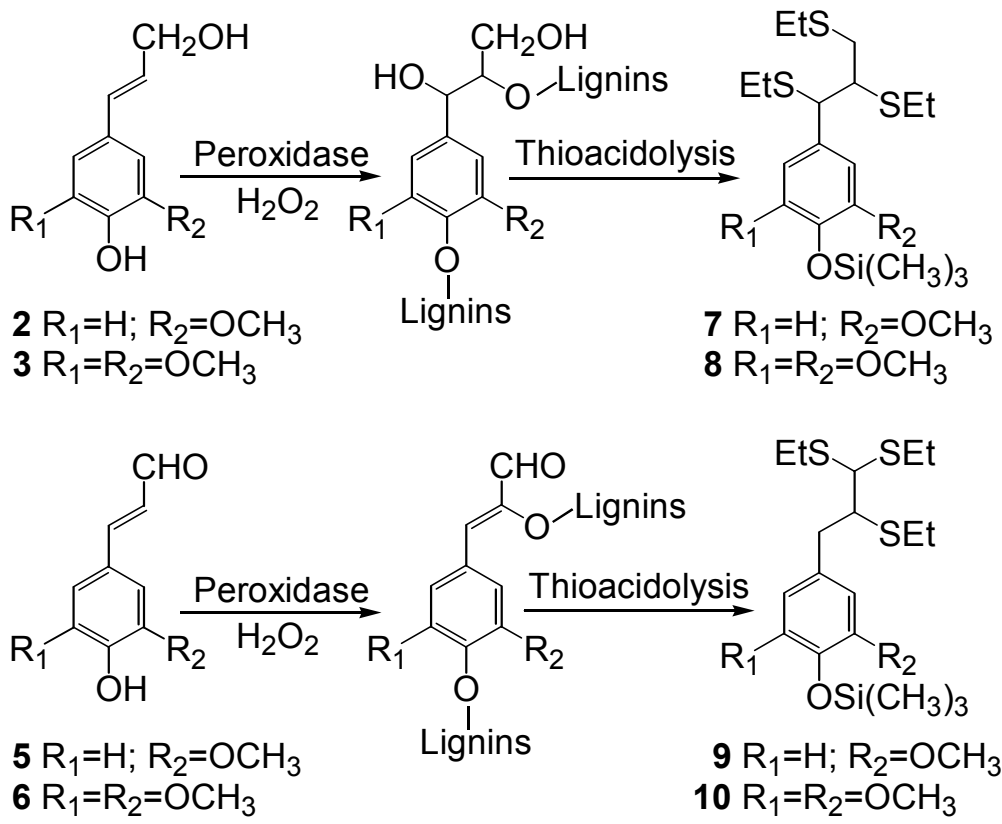

\section{Scheme 2}

From these results, it may be concluded that the $p$-hydroxycinnamyl alcohol $/ p$ hydroxycinnamyl aldehyde ratios of the $\beta-O-4$ lignin fraction are independent of the lignin monomer composition, and that these ratios have been largely conserved during land plant evolution. 


\section{Experimental Section}

Plant growth conditions. Young branches of Ginkgo biloba, Cycas revoluta, Cupressus sempervirens, Taxus baccata, Pinus halepensis, Araucaria araucana, Araucaria heterophylla and Populus alba were harvested in April and May from trees at least 5 years old, growing in the Campus of the University of Murcia (SE of Spain). Seedlings of Zinnia elegans L (cv. Envy), Capsicum annuum, and Ephedra viridis were grown for 14, 30 and 90 days, respectively, in a greenhouse under daylight conditions. Selaginella martensii cv jori was purchased from a local nursery. Pteridium aquilinum and Dryopteris filis-max were harvested in the field at $1=43^{\circ}$ $19.799^{\prime} \mathrm{N}, \mathrm{L}=8^{\circ} 24.263^{\prime} \mathrm{W}$, and $\mathrm{l}=43^{\circ} 15.871^{\prime} \mathrm{N}, \mathrm{L}=8^{\circ} 09.765^{\prime} \mathrm{W}$, respectively, in the $\mathrm{NW}$ of Spain.

Isolation of cell walls and thioacidolysis analyses. Cell walls were prepared by a Triton X-100 washing procedure. ${ }^{6}$ Thioacidolysis of lignifying cell walls, which solubilizes the $\beta-O-4$ lignin core, was performed as described. ${ }^{6}$ GC-MS analyses were performed using a Hewlett Packard 5890 Series II gas chromatograph, an HP 5972 mass spectrometer and an HP5 (30 m x $0.25 \mathrm{~mm}$ I.D.) column. Mass spectra were recorded at $70 \mathrm{eV} .{ }^{6}$ Compounds 7-10 were analyzed using GCMS chromatograph and were identified by superimposable of the mass spectra with those reported in the literature. ${ }^{6}$

\section{Acknowledgements}

This work was supported by grants from the Fundación Séneca (00545/PI/04), XUGA (PGIDIT04RAG-503018PR) and MCYT (BOS2002-03550). LVGR holds fellowship (FPI) from the MCYT.

\section{References}

1. Ros Barceló, A. Int. Rev. Cytol. 1997, 176, 87.

2. (a) Ralph, J.; Lundquist, K.; Brunow, G.; Lu, F.; Kim, H.; Schatz, P. F.; Marita, J. M.; Hatfield, R. D.; Christensen, J. H.; Boerjan, W. Phytochem. Rev. 2004, 3, 29. (b) Dixon, R. A.; Chen, F.; Guo, D.; Parvathi, K. Phytochemistry 2001, 57, 1069. (c) Kishimoto, T.; Uraki, Y.; Ubukata, M. Org. Biomol. Chem. 2006, 4, 1343.

3. Lapierre, C.; Pollet, B.; and Rolando, C.; Res. Chem. Intermed. 1995, 21, 397.

4. (a) Kim, H.; Ralph, J.; Yahiaoui, N.; Pean, M.; Boudet, A. M. Org. Lett. 2000, 2, 2197. (b) Kim, H.; Ralph, J.; Lu, F.; Pilate, G.; Leple, J. C.; Pollet, B.; Lapierre, C. J. Biol. Chem. 2002, 277, 47412.

5. Ito, T.; Kawai, S.; Ohashi, H.; Higuchi, T. J. Wood Sci. 2002, 48, 409.

6. Pomar, F.; Merino, F.; Ros Barceló, A. Protoplasma 2002, 220, 17. 